\title{
DETERMINAÇÃO DE LAMIVUDINA EM MATÉRIA PRIMA E SOLUÇÃO ORAL POR ESPECTROMETRIA UV COM FORMAÇÃO DO COMPLEXO AZUL DE TIMOL E CROMATOGRAFIA LÍQUIDA DE ALTA EFICIÊNCIA
}

\section{DETERMINATION OF LAMIVUDINE IN RAW MATERIAL AND ORAL SOLUTION BY UV SPECTROSCOPY WITH THYMOL BLUE COMPLEX FORMATION AND HIGH PERFORMANCE LIQUID CHROMATOGRAPHY}

\author{
Núbia C. de Paula ${ }^{1}$; Hérica N.C. Cirilo²; Valéria R. Silva³ ${ }^{3}$ Petrhus S. Kluthcouski; Valéria \\ de Oliveira ${ }^{*}$. \\ ${ }^{1}$ Laboratório de Saúde Pública "Dr. Giovanni Cysneiros”, Secretaria Estadual do Estado de Goiás; Avenida \\ Contorno n. 3556, Jardim Bela Vista, CEP 74853-120, Goiânia-GO, Brasil. \\ ${ }^{2}$ Laboratório de Controle de Qualidade de Medicamentos (LCQM/FF/UFG); \\ ${ }^{3}$ Bolsistas de Iniciação Científica CNPq/ANVISA; \\ ${ }^{4}$ Docente do Programa de Pós-Graduação em Ciências Farmacêuticas da UFG, Faculdade de Farmácia, \\ Universidade Federal de Goiás, Praça Universitária esq. com Primeira Avenida, Caixa Postal 131, CEP 74605- \\ 220, Goiânia-GO, Brasil.
}

*Autor para correspondência: valeria@farmacia.ufg.br

Recebido em 21/11/2006 - Aceito em 20/12/2006

\begin{abstract}
RESUMO: Espectrofotometria na região do UV por formação do complexo com azul de timol (Método I) e cromatografia líquida de alta eficiência (Método II) foram desenvolvidos, validados e aplicados na determinação quantitativa da lamivudina em matéria prima e solução oral. No método espectrofotométrico as leituras foram realizadas a $270 \mathrm{~nm}$ com a formação do complexo de azul de timol em solução de metanol 9:1. No cromatográfico as condições foram uma coluna LiChrospher ${ }^{\circledR} 100$ RP18 $(250 \times 4,6 \mathrm{~mm}, 0,5 \mu)$, metanol: água como fase móvel e fluxo de $1,0 \mathrm{~mL}$ por minuto com detecção no UV a $270 \mathrm{~nm}$. O tempo de retenção da lamivudina foi 2,7 min. As curvas de calibração foram lineares em intervalos de concentração de 8,0 a 16,0 $\mathrm{g} / \mathrm{mL}$ para o método I e de 20,0 a $100,0 \mathrm{~g} / \mathrm{mL}$ para o método II com coeficientes de correlação de 0,9999 e 0,9985 respectivamente. O desvio padrão relativo foi de $0,38 \%$ para matéria prima e de $0,89 \%$ para a solução oral pelo Método I. Para o método II, os valores foram $0,42 \%$ e $0,90 \%$ respectivamente. A porcentagem de recuperação foi de aproximadamente $100 \%$ para ambos os métodos. Os resultados mostraram que o método cromatográfico (Método II) é o mais adequado para a determinação da lamivudina na solução oral, uma vez que o excipiente interferiu nos resultados obtidos no método I.
\end{abstract}

PALAVRAS CHAVE: Lamivudina, solução oral, espectrofotometria UV, cromatografia líquida de alta eficiência.

ABSTRACT: Ultraviolet spectrophotometric with tymol blue complex (Method I) and high performance liquid chromatographic (Method II) methods were developed. The validated methods were applied for quantitative determination of lamivudine in raw material and oral solution. UV spectrophotometric determinations were made using thymol blue complex at $270 \mathrm{~nm}$, with ethanol solution 9:1. Liquid chromatographic analysis was carried out on a LiChrospher ${ }^{\circledR} 100 \mathrm{RP} 18(250 \times 4.6 \mathrm{~mm}, 0.5 \mu)$ column. Methanol:water $(50: 50 \mathrm{v} / \mathrm{v})$ was used as mobile phase at a flow rate of $1.0 \mathrm{~mL} / \mathrm{min}$ with UV detection at $270 \mathrm{~nm}$. The retention time of lamivudine was 2.7 min. Analytical curves were linear within a concentration range from 8.0 at $16.0 \mathrm{~g} / \mathrm{mL}$ for Method I and to 20.0 at $100.0 \mathrm{~g} / \mathrm{mL}$, for method II, with correlation coefficients of 0.9999 and 0.9985 , respectively. The relative standard deviation (RSD) 
was $0.38 \%$ for raw material and $0.89 \%$ for oral solution, using method I. The corresponding values were $0.42 \% \%$ and $0.90 \%$ using method II. The percentage recoveries were around $100 \%$ for both methods. The results showed that method II was the most appropriated for lamivudine determination in oral solution, because the excipent can be interfere in the results of method $I$.

KEYWORDS: Lamivudine, oral solution, UV spectrophotometry, high performance liquid chromatography

\section{INTRODUÇÃO}

Após a descoberta da zidovudina em 1964 como anti-HIV, vários análogos foram sintetizados com o objetivo de se obter fármacos mais eficazes, a lamivudina é um deles, capaz de inibir a enzima transcriptase reversa. A atividade antiviral ocorre após a sua fosforilação pelas quinases, interrompendo a replicação viral (SOUZA \& ALMEIDA, 2003). A lamivudina é um dos análogos sintéticos de nucleotídeos com atividade sobre o vírus da imunodeficiência humana mais utilizada. Quimicamente é a 2'-deoxi-3'-tiacitidina (3TC) ou (2R-cis)-4amino-1-[2-(hidroximetil)-1,3-oxatiolano-5-il]-2(1H)-pirimidina (Fig.1A). Está disponível em várias formas farmacêuticas destacando-se entre elas, a solução oral e os comprimidos, onde ela pode ser o único princípio ativo ou estar em associação com outros antiretrovirais.

Alguns métodos analíticos são descritos na literatura para determinação da lamivudina, como por exemplo, os de cromatografia líquida de alta eficiência aplicada aos fluidos biológicos (KENNEY, et al., 2000, PEREIRA, et al., 2000; MOORE, et al., 2000; FAN \& STEWART, 2001; MESPLET, et al., 2001; SIMON, et al., 2001; ZHENH, et al., 2001; VOLOSOV, et al., 2002).

Recentemente o alvo dos estudos têm sido as metodologias para determinação da lamivudina em formas farmacêuticas, principalmente os comprimidos. Tanto a cromatografia líquida de alta eficiência (USLU \& ÖZKAN, 2002; ANBAZHAGAN, et al., 2005; FERNANDES, et al., 2006; KAPOOR, et al., 2006a; KAPOOR, et al., 2006b; KAPOOR, et al., 2006c; SARKAR, et al., 2006), quanto a espectrometria na região do UV ou derivada (USLU \& ÖZKAN, 2002; KAPOOR, et al., 2006; SARKAR, et al., 2006) e mesmo a cromatografia em camada delgada de alta eficiência (ANBAZHAGAN, et al., 2005) têm sido avaliadas. Estas iniciativas se devem ao fato da necessidade de garantir a quantidade adequada de princípio ativo, fundamental para a eficácia terapêutica e que muitas vezes pode ser afetada por problemas inerentes a formulação e a conservação do produto. Métodos espectrométricos utilizando complexo com azul de tymol (Fig. 1B) têm sido empregados na literatura para determinação de outros compostos em solução (BALDERAS-HERNANDEZ, et al., 2003), mas não foram encontrados na literatura para determinação da lamivudina. O objetivo deste trabalho foi o de desenvolver métodos analíticos alternativos, sensíveis e eficientes para determinação da lamivudina em matéria prima e solução oral.

(A)<smiles></smiles>

(B)<smiles>CC1=CC(=O)C(C(C)C)=CC1=C(c1cc(C(C)C)c(O)cc1C)c1ccccc1S(=O)(=O)O</smiles>

Figura 1. Estruturas químicas da lamivudina $(A)$ e do azul de timol (B).

\section{MATERIAL E MÉTODOS}

\section{Equipamentos}

Espectrofotômetro UV/VIS modelo GBC 911A e Cintra 10e com cubeta de quartzo de 1,0 cm foram utilizados para medidas de absorbância e varreduras respectivamente. O sistema cromatográfico empregado foi um Cromatógrafo Gilson modelo 3321, detector UV/VIS modelo 152, duas bombas e válvula injetora Rheodyne R77251, uma coluna analítica Lichrospher ${ }^{\circledR} 100 \mathrm{RP}-18(250 \times 4,6 \mathrm{~mm} \times 0,5 \mu)$. Câmaras climáticas Nova Ética ${ }^{\circledR}$ modelo 310 foram usadas para o armazenamento das amostras de solução oral. 


\section{Substâncias químicas de referência, reagentes e soluções}

Lamivudina 99,89\% (Hetero Drugs Ltda, Índia) foi utilizada como substância química de referência (SQR) sem purificação. Todos os demais reagentes utilizados foram grau analítico e os solventes empregados como fase móvel foram grau HPLC/UV. Água destilada foi purificada pelo sistema Milli $Q^{\circledR}$ Simplicity (Millipore, Milford, MA, USA). Amostras comerciais de matéria prima, solução oral de lamivudina contendo $10 \mathrm{mg} / \mathrm{mL}$ e solução oral após tratamento térmico em câmara climatizada na temperatura de $50^{\circ} \mathrm{C} \pm 2^{\circ} \mathrm{C}$, e umidade relativa de $90 \% \pm 5 \%$, durante 30, 60 e 90 dias (BRASIL, 2002) foram selecionadas para análise.

\section{Métodos}

\section{Espectrometria no UV pela formação do complexo com o azul de timol (Método I)}

Para estabelecer o solvente e o pH adequados para a formação do complexo uma série de experimentos foram realizados com etanol, tampão borato alcalino, tampão $\mathrm{HCl}$, solução de $\mathrm{H}_{2} \mathrm{SO}_{4} 0,005 \mathrm{M}, \mathrm{NaOH} 0,1 \mathrm{M}$, na ausência e presença do azul de timol e lamivudina, realizando-se varreduras nas faixas de ultravioleta e visível no sentido de avaliar a formação ou não de complexo. As condições ótimas para o desenvolvimento do método foram estabelecidas variando parâmetros como a concentração do corante azul de timol e posteriormente da lamivudina, observando os efeitos produzidos na absorbância. Experimentos em que as concentrações do agente complexante e da lamivudina foram alteradas puderam avaliar a faixa de análise mais adequada. Para estabelecer a faixa de concentração linear, uma curva de calibração foi realizada preparando-se soluções da lamivudina substância química de referência com concentrações variando de 8,0 a $16,0 \mu \mathrm{g} / \mathrm{mL}$ e as absorbâncias dessas soluções, em triplicata foram medidas a $270 \mathrm{~nm}$ contra um branco de etanol 9:1. O tempo de estabilidade do complexo formado foi avaliado de 0 a 60 minutos pelo cálculo do coeficiente de regressão linear calculado para as várias leituras dos valores obtidos na curva de calibração.

\section{Cromatografia líquida de alta eficiência (Método II)}

As condições cromatográficas empregadas foram uma fase móvel contendo metanol: água (50:50 v/v) coluna analítica Lichrospher ${ }^{\Theta} 100 \mathrm{RP}-18(0,5 \mu)(150 \times 4,6 \mathrm{~mm})$, com um fluxo de $0,8 \mathrm{~mL} / \mathrm{min}$ e a temperatura ambiente $\left(25 \pm 2^{\circ} \mathrm{C}\right)$, com detecção no UV a $270 \mathrm{~nm}$. $10 \mathrm{mg}$ da lamivudina substância química de referência foram rigorosamente pesadas e dissolvidas em metanol, completando-se o volume para $100 \mathrm{~mL}$ em balão volumétrico. Dessa solução $(100,0 \mathrm{~g} / \mathrm{mL})$, foram retiradas alíquotas de 5,0 a $20,0 \mathrm{~mL}$, obtendo-se concentrações respectivas de 20, 40,60, $80 \mathrm{~g} / \mathrm{mL}$. Estas soluções foram analisadas em duplicata e a curva de calibração foi construída plotando-se concentração de lamivudina versus área.

Com o objetivo de avaliar a seletividade dos métodos foram realizadas varreduras na faixa de 200 a $600 \mathrm{~nm}$ com didanosina, zidovudina e os excipientes (placebo) na presença e ausência do azul de timol, e amostras de solução oral submetidas a tratamento térmico foram analisadas. Parâmetros como linearidade, precisão, repetibilidade (precisão intra-corrida), precisão intermediária (precisão inter-corrida), exatidão (recuperação), assim como percentual de recuperação foram avaliados (BRASIL, 2003).

\section{RESULTADOS E DISCUSSÃO}

No método I, azul de timol em solução etanólica 9:1 apresentou-se como o solvente de escolha, conforme os resultados apresentados na Tabela 1.

Tabela 1. Avaliação da formação do complexo lamivudina e azul de timol em função do pH e das soluções utilizadas.

\begin{tabular}{lccc}
\hline Solução & pH & Formação de complexo & Abs máxima \\
\hline Tampão borato alcalino & 6,0 & Ausente & ---- \\
Tampão ácido clorídrico & 7,0 & Ausente & ---- \\
Hidróxido de sódio 0,1M & 9,0 & Ausente & ---- \\
Ácido sulfúrico $0,005 \mathrm{M}$ & 2,0 & Ausente & $-270 \mathrm{~nm}$ \\
Solução etanólica $9: 1$ & 5,0 & presente & 27 \\
\hline
\end{tabular}

Após a formação do complexo o máximo de absorção deslocou-se de $600 \mathrm{~nm}$ para $270 \mathrm{~nm}$ como pode ser observado na Fig.2. 
(A)

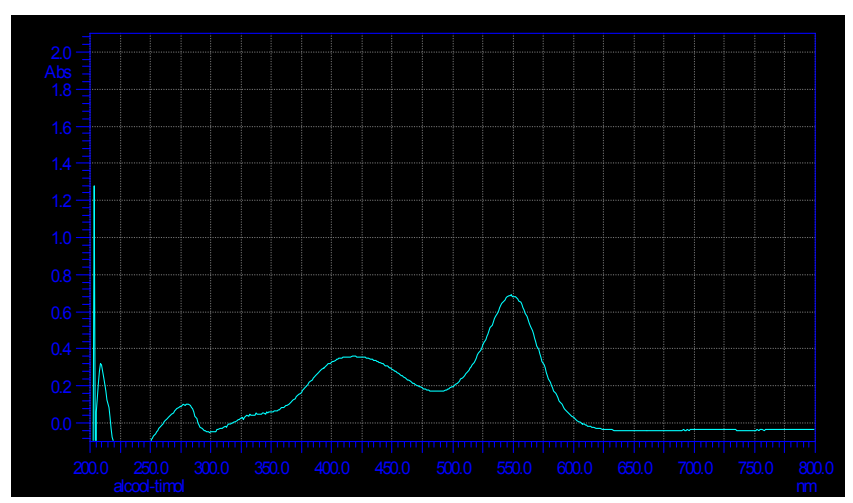

(B)

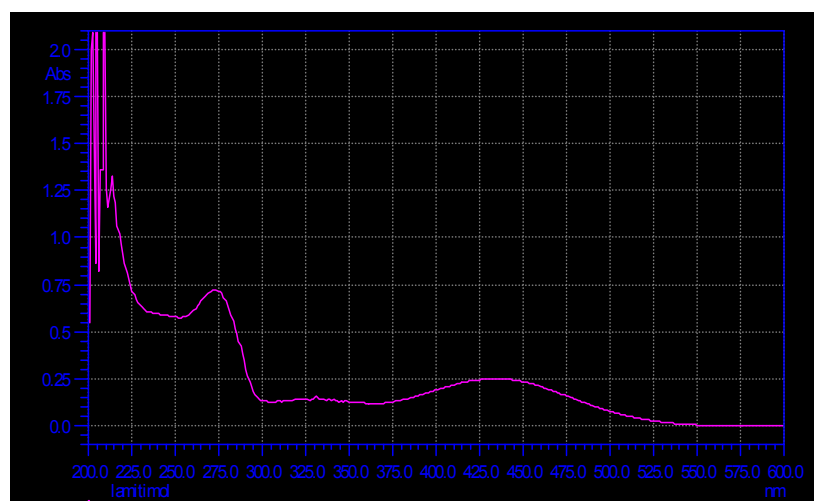

Figura 2. Espectros UV da solução etanólica de azul de timol apresentando o máximo de absorção em 550nm (A) e da solução etanólica de lamivudina complexada ao azul de timol com máximo de absorção em 270nm (B) (varredura no intervalo de 600-200nm).

A curva de calibração apresentou linearidade no intervalo avaliado com uma equação de regressão linear $(y=0,0097 x+0,1728)$ e o coeficiente de correlação $(r)$ de 0,9999 . A melhor concentração de azul de timol foi definida como $8,7 \times 10^{-4}$ molar. O complexo permanece estável por até 60 minutos. A precisão do método proposto foi testada pela análise de seis amostras em replicatas da matéria-prima e solução oral os resultados encontrados estão apresentados na tabela 3. A precisão intermediária que é a concordância entre os resultados do mesmo laboratório obtidos em dias diferentes, por analistas diferentes figura na tabela 4.

Tabela 3. Parâmetros estatísticos e resultados obtidos na determinação de lamivudina presente na matéria prima (1) e solução oral (2), pelos métodos I e II.

\begin{tabular}{lcccc}
\hline $\begin{array}{l}\text { Parâmetros } \\
\text { estatísticos }\end{array}$ & \multicolumn{2}{c}{ Método (I) } & \multicolumn{2}{c}{ Método (II) } \\
\hline Amostra & $\mathbf{1}$ & $\mathbf{2}$ & $\mathbf{1}$ & $\mathbf{2}$ \\
CV(\%) & 0,38 & 0,89 & 0,42 & 0,90 \\
Teor declarado (\%) & 99,8 & 100,0 & 99,8 & 100,0 \\
Teor encontrado (\%) & 99,2 & 126,1 & 100,61 & 101,20 \\
Média +e.p.m & $99,2 \pm 0,13$ & $126,1 \pm 0,46$ & $100,61 \pm 0,42$ & $101,20 \pm 0,90$ \\
\hline
\end{tabular}

Tabela 4: Resultados obtidos na avaliação da precisão intermediária, interdia e interanalista no doseamento da matéria-prima e solução oral pelos métodos I e II.

\begin{tabular}{lccc}
\hline \multicolumn{1}{c}{ Matéria-prima } & $\begin{array}{c}\text { Método (I) } \\
\text { Teor\% médio }\end{array}$ & $\mathbf{e p m}^{*}$ & CV\% \\
\hline Dia 1 (analista A) & 99,2 & 0,13 & 0,38 \\
Dia 2 (analista A) & 99,2 & 0,13 & 0,33 \\
Analista B Solução oral & 98,3 & 0,44 & 1,11 \\
\hline \multicolumn{1}{c}{ Matéria-prima } & & \\
\hline Dia 1 (analista A) & 126,1 & 0,46 & 1,13 \\
Dia 2 (analista A) & 123,5 & 0,28 & 0,69 \\
Analista B & 120,9 & 0,25 & 0,61 \\
\hline & Método (II) & \\
Dia 1 (analista A) & Teor\% médio & $\mathbf{e p m}^{*}$ & CV\% \\
Dia 2 (analista A) & 100,61 & 0,20 & 0,42 \\
Analista B & 100,59 & 0,21 & 0,54 \\
\hline \multicolumn{1}{c}{ Solução oral } & 101,65 & 0,30 & 0,40 \\
\hline Dia 1 (analista A) & & & \\
Dia 2 (analista A) & 101,20 & 0,40 & 0,90 \\
Analista B & 101,44 & 0,40 & 0,80 \\
\hline
\end{tabular}

* epm: erro padrão da média 
No doseamento da solução oral verificou-se um aumento do teor da lamivudina, sugerindo uma interferência dos excipientes. Foram realizadas leituras da solução do excipiente nas mesmas concentrações presentes na solução oral, o que demonstrou uma absorção na mesma região da lamivudina complexada ao azul de timol (Fig. 3). Provavelmente os excipientes formam um complexo com o azul de timol e parte da lamivudina em solução, e mesmo apresentando um menor coeficiente de absortividade molar (Fig.3 F), provoca um efeito aditivo aumentando o valor de absorbância em $270 \mathrm{~nm}$ e consequentemente a concentração da lamivudina.

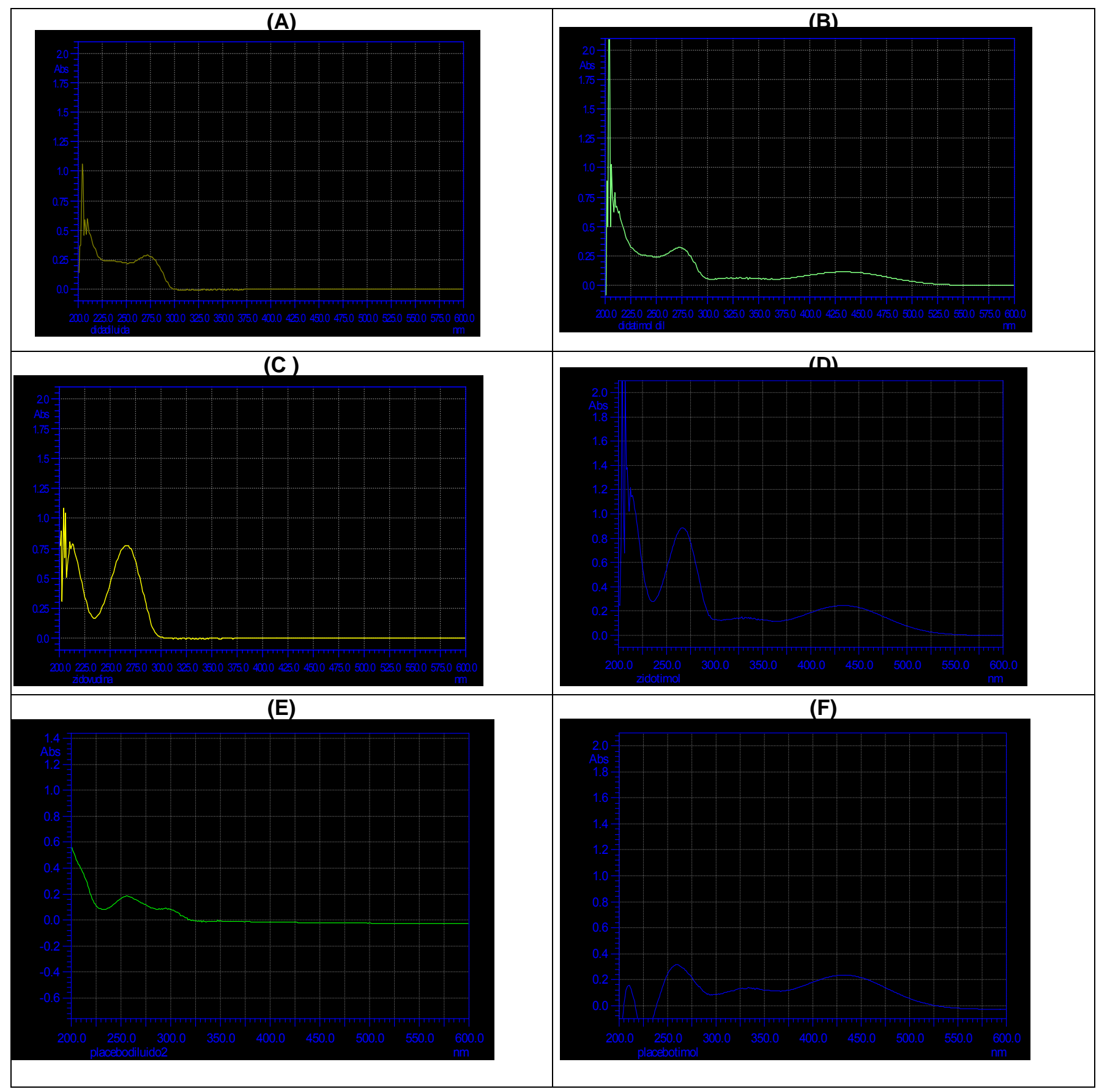

Fig 3. Espectros UV de absorção na região de 200 a $600 \mathrm{~nm}$ das soluções de (A) didanosina, (B) didanosina complexada ao azul de timol, (C) zidovudina, (D) zidovudina complexada, (E) placebo e (F) placebo complexado ao azul de timol.

Quanto á seletividade da formação do complexo, os espectrogramas representados na figura 3 mostram que a formação do complexo com azul de timol ocorre indiscriminadamente, com a didanosina, zidovudina ou com o excipiente presente no placebo, inviabilizando a aplicação do método I em amostras contendo associações e na solução oral. 
No método II, o cromatograma da lamivudina substância química de referência (A) e da solução oral (B) podem ser observados na fig. 4. Os tempos de retenção observados foram de 2,5 min. para a lamivudina e 10,6 min. para o excipiente contido no placebo. A curva de calibração construída em intervalos de concentração de 20 a $100 \mathrm{~g} / \mathrm{mL}$ apresentou linearidade com uma equação de regressão linear $\left(y=7,0 \times 10^{-3} x+8,0 \times 10^{-3}\right)$ e o coeficiente de correlação $(r)$ de 0,9985 . Os resultados referentes á precisão do método, avaliada pelo coeficiente de variação podem ser observados na tabela 3 e os da exatidão na tabela 4.

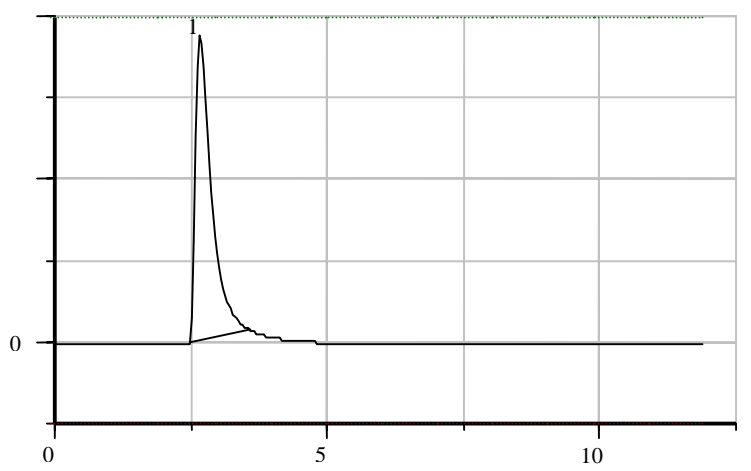

(A)

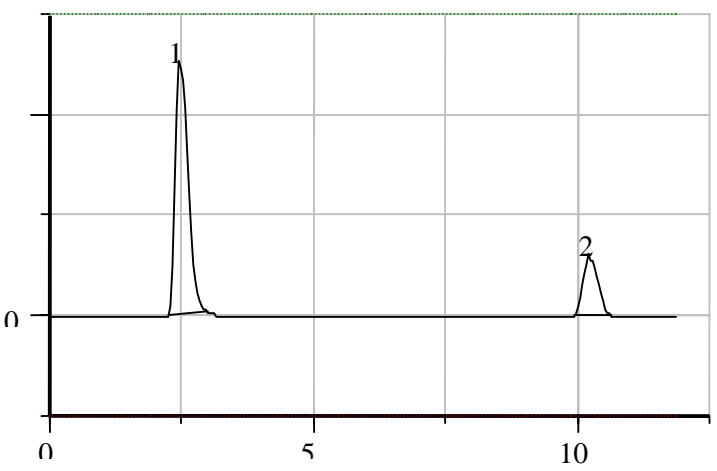

(B)

Figura 4. Cromatogramas: (A) Lamivudina $40 \mathrm{~g} / \mathrm{mL}$; (B) solução oral contendo $30 \mathrm{~g} / \mathrm{mL}$. Condições cromatográficas: fase móvel: metanol/água (50:50), fluxo $0,8 \mathrm{ml} / \mathrm{min}$ e detecção UV a $270 \mathrm{~nm}$; Lichrospher ${ }^{{ }^{3}} 100$ RP-18 $(250 \times 4,6 \mathrm{~mm}, 5 \mu \mathrm{m})$, temperatura ambiente $\left(25 \pm 2^{\circ} \mathrm{C}\right)$.

A exatidão dos métodos foi determinada para a solução oral, com a adição de concentrações conhecidas da substância química de referência e os resultados obtidos são apresentadas na tabela 5.

Tabela 5. Resultados obtidos na recuperação da lamivudina substância química de referência adicionada á solução oral analisada pelos métodos propostos.

\begin{tabular}{lcccccc}
\hline \multicolumn{3}{c}{ Método (I) } & \multicolumn{3}{c}{ Método (II) } \\
\hline Amostra & \multicolumn{3}{c}{$\begin{array}{c}\text { Recuperação } \\
(\%)\end{array}$} \\
& $\begin{array}{c}\text { Adicionado } \\
\mathrm{g} / \mathrm{mL})\end{array}$ & Encontrado & \multicolumn{2}{c}{$\begin{array}{c}\text { Recuperação } \\
(\%)\end{array}$} \\
\hline Solução oral & 0,8 & 0,78 & 97,6 & 70 & 69,51 & 99,3 \\
& 1,0 & 0,96 & 96,5 & 100 & 102,0 & 102 \\
& 12 & 11,9 & 99,7 & 120 & 127,2 & 106 \\
\hline
\end{tabular}

Após serem submetidas ao tratamento térmico as amostras de solução oral analisadas pelo método I e II, foi observado uma diminuição de aproximadamente $10,0 \%$ do teor da lamivudina em ambos. Provavelmente os produtos de decomposição não reagem com o azul de timol formando complexo, pois se isto ocorresse o teor permaneceria constante. No método II embora os produtos de degradação não fossem observados no cromatograma, este fato e a diminuição da concentração da lamivudina indicam uma perda de absorção a $270 \mathrm{~nm}$ pelos produtos de decomposição formados.

\section{Conclusões}

Os dados apresentados indicam que os dois métodos são úteis na determinação de lamivudina em matéria prima, o método I, entretanto apresenta a limitação de sofrer interferência do excipiente presente na solução oral. O método II não sofre essa interferência e pode ser usado inclusive para uma avaliação da estabilidade da solução oral.

\section{REFERÊNCIAS BIBLIOGRÁFICAS}

ANBAZHAGAN, S., et al. Simultaneous quantification of stavudine, lamivudine and nevirapine by UV spectroscopy,reverse phase HPLC and HPTLC in tablets. Journal of Pharmaceutical and Biomedical Analysis. vol 39, p 801-804, 2005. 
BALDERAS-HERNANDEZ, P., et al. Spectrophotometric study of the system $\mathrm{Hg}$ (II)-thymol blue- $\mathrm{H}_{2} \mathrm{O}$ and its evidence through electrochemical means. Spectrochimica Acta Part A, 2003.

BRASIL.Ministério da Saúde. Agência Nacional de Vigilância Sanitária, Resolução - RE $n^{\circ} 560$, de 2 de abril de 2002.Guia para realização de estudos de estabilidade. Diário oficial da união, 03 de abril de 2002.

BRASIL.Ministério da Saúde. Agência Nacional de Vigilância Sanitária, Resolução - RE nº 899, de 29 de maio de 2003. Guia para validação de métodos analíticos e bioanalíticos. Diário oficial da União, 02 de junho de 2003.

FAN. B; STEWART, J. T. Determination of zidovudine/lamivudina/nevirapine in human plasma using ion-pair HPLC. Journal of Pharmaceutical and Biomedical Analysis, v.28, p.903-908, 2001.

FARMACOPÉIA BRASILEIRA: 4. ed. São Paulo: Editora Atheneu, parte 2, fascículo 3, 2002.

FERNANDES. C., et al. Dissolution test for lamivudine tablets: Optimization and statistical analysis Journal of Pharmaceutical and Biomedical Analysis. v 42, n 5, p 601-606, 2006.

HOETELMANS, R. M. W., et al. Quantitative determination of (-)-deoxy-3'-thiacytidine (lamivudina) in human plasma, saliva and cerebrospinal fluid by high-performance liquid chromatography with ultraviolet detection. Journal of chromatography. p-387-394, 1998.

KAPOOR, N.; KHANDAVILL, S. \& PANCHAGNULA, R. Development and validation of RP-HPLC and ultraviolet spectrophotometric methods of analysis for the quantitative estimation of antiretroviral drugs in pharmaceutical dosage forms. Journal of Chromatography B, v. 830, p. 349-354, 2006a.

KAPOOR, N.; KHANDAVILLI, S. \& PANCHAGNULA, R. Simultaneous determination of lamivudine, stavudine and nevirapine in antiretroviral fixed dose combinations by high performance liquid chromatography. Analytica Chimica $\begin{array}{lllll}\text { Acta. } & \text { V. } & \text { p } & \text { 2006b. }\end{array}$

KAPOOR, N.; KHANDAVILLI, S. \& PANCHAGNULA, R. Simultaneous determination of lamivudine and stavudine in antiretroviral fixed dose combinations by first derivative spectrophotometry and high performance liquid chromatography. Journal of Pharmaceutical and Biomedical Analysis, v. 41, p.761-765, Jun 2006/C.

KENNEY, K. B., et al. Simultaneous determination of zidovudine and lamivudina in human serum using HPLC with tandem mass spectrometry. Journal of Pharmaceutical and Biomedical Analysis. v. 22, p. 967-983, 2000.

MESPLET, et al. Simultaneous quantitation of nucleoside HIV-1 reverse transcriptase inhibitors by short-end injection capillary electrochomatography on a $\beta$-cyclodextrin-bonded silica stationary phase. Journal of chromatography A, p.161-168, 2001.

MOORE. J. D., et al. Simultaneous quantitation of the 5'-triphosphate metabolites of zidovudine, lamivudine, and stavudine in peripheral mononuclear blood cells of HIV infected patients by high-performance liquid chromatography tandem mass spectrometry. Journal of the American Society for Mass Spectrometry. v. 11, p.1134-1143, 2000.

PEREIRA, A. S., et al. Simultaneous determination lamivudine of zidovudine and concentrations in human seminal plasma using high-performance liquid chromatography tandem mass spectrometry. Journal of Chromatography $B$, p.173-183, 2000.

SARKAR M.; KHANDAVILLI S.; PANCHAGNULA, R. Development and validation of RP-HPLC and ultraviolet spectrophotometric methods of analysis for the quantitative estimation of antiretroviral drugs in pharmaceutical dosage forms. Journal of Chromatography B, v 830, n 2, 18, p. 349-354, 2006.

SIMON, V. A; THIAM, M. D; LIPFORD, L. C. Determination of serum levels of thirteen human immunodeficiency virus-suppressing drugs by high-performance liquid chromatography. Journal of chromatography A, p. 447-453, 2001.

SOUZA, M. V. N. \& ALMEIDA, M. V. Drogas anti-HIV: passado, presente e perspectivas futuras.Química Nova. v.26, p.366-372, 2003. 
UNITED STATES PHARMACOPEIA - THE NATIONAL FORMULARY - 28 ed. Rochville, 2005.

USLU, B. \& OZKAN, S. A. Determination of lamivudine and zidovudine in binary mixtures using first derivative spectrophotometric, first derivative of the ratio-spectra and high-performance liquid chromatography-UV methods. Analytica Chimica Acta. p.175-185, 2002.

VOLOSOV A.; ALEXANDER C.; TING, L.; SOLDIN, S. J. Simple rapid method for quantification of antiretrovirals by liquid chromatography—tandem mass-spectrometry. Clinical Biochemistry. v 35, n. 2, p.99-103, 2002.

ZHENG, J. J; WU, S. T; EMM, T. A. High-performance liquid chromatographic assay for the determination of 2'deoxy-3'-thiacytidine (lamivudine) in human plasma. Journal of chromatography B. p. 195-2001, 2001. 